\title{
Herpes simplex virus: Drug resistance and new treatment options using natural products (Review)
}

\author{
TABEA ANNE MUNDINGER ${ }^{1}$ and THOMAS EFFERTH ${ }^{2}$ \\ ${ }^{1}$ Institute of Pharmacy and Molecular Biotechnology, University of Heidelberg; \\ ${ }^{2}$ Pharmaceutical Biology (C015), German Cancer Research Center, Heidelberg, Germany
}

Received May 30, 2008; Accepted June 9, 2008

DOI: $10.3892 / \mathrm{mmr} 00000001$

\begin{abstract}
As herpes simplex infections are very common worldwide, new treatment options are of high importance, especially for immunosuppressed individuals. Although the standard treatment options have shown high effectiveness for decades, the risk that drug resistance will emerge remains significant. It is therefore important that new drug targets and new treatments are investigated, not just in preliminary tests, but also in vitro, in vivo and by clinical testing. One valuable source for new treatments is the abundance of molecules from natural products that have been shown to possess antiviral properties. Several potential candidates for the development of new anti-herpes drugs are discussed in this short review.
\end{abstract}

\section{Contents}

1. Standard treatment of herpes simplex virus infections

2. Natural products with anti-herpes simplex virus activity

3. Conclusions

\section{Standard treatment of herpes simplex virus infections}

Worldwide, herpes simplex virus (HSV)-1 and -2 infections are very common. HSV-2 mainly causes genital herpes and is transmitted sexually, while HSV-1 is usually transmitted during childhood and causes a variety of herpes symptoms, including lesions on the facial and genital areas $(1,2)$.

Once an HSV infection occurs, the virus will establish latency in the ganglia of the peripheral nervous system (3) and can reactivate and multiply in significant numbers within lesions, allowing for the infection of a new host. In immunocompetent individuals, this can be painful and bothersome, but

Correspondence to: Dr Thomas Efferth, Pharmaceutical Biology (C015), German Cancer Research Center, Im Neuenheimer Feld 280, 69120 Heidelberg, Germany

E-mail: t.efferth@dkfz.de

Key words: anti-viral agents, chemotherapy, drug resistance, herpes simplex virus, natural products, pharmacognosy is rarely life threatening. Consequently, the dangers of herpes simplex are underestimated by most individuals, although HSV infections can become very prolonged and severe in patients with an impaired immune system or in neonates $(4,5)$. Additionally, ocular diseases caused by herpes infections are one of the leading causes of blindness in the western world (6).

A US study conducted by Xu et al showed that HSV infections seem to be decreasing, especially among the youth. For HSV-2, seroprevalence has decreased from 21 (1988-1994) to 17\% (1999-2002), while HSV-1 seroprevalence has decreased overall from 62 to $57.7 \%$. Nonetheless, in recent years the incidence of genital herpes caused by HSV-1 has increased significantly in some developed countries (7), probably because a decreased likelihood of contracting HSV-1 infection during early childhood has led to increased chances of infection during sexual contact. This is particularly worrisome as genital herpes infections have been shown to at least double the risk of sexually-acquired HIV infections $(5,8,9)$, with the prevalence of HSV-2 in HIV-infected individuals estimated to be as high as $90 \%$ in certain populations (10).

With the discovery of acyclovir (ACV) in 1974 (11) and later of penciclovir (PCV) (12), antiviral therapy was revolutionized. These guanine analogues are highly selective in fighting active HSV outbreaks because of their specific mode of action and activation. They have a high affinity for viral thymidine kinase (TK), while cellular TK only causes minimal phosphorylation. This means that triphosphate is mainly produced in virus-infected cells, where it competes with dGTP and blocks viral DNA polymerase by inhibiting chain elongation $(13,14)$. The excellent clinical safety of the substances is further achieved by the low affinity of triphosphates to cellular DNA polymerase $(13,15,16)$.

Current second-line substances for HSV treatment are the pyrophosphate analogue, foscarnet, and the acyclic nucleoside phosphonate derivative, cidofovir. Neither are dependent on prior virus-specific activation, and both target viral DNA polymerase. Foscarnet binds to DNA polymerase and prevents the cleavage of pyrophosphate from deoxynucleotide triphosphates without requiring prior phosphorylation (17). Cidofovir is phosphorylated by cellular kinases, and in its diphosphate form acts as a potent inhibitor of viral DNA polymerase $(18,19)$.

With almost three decades of ACV as the mainstay therapy for HSV infections, it is surprising to note that resistance has not become a clinically significant problem in normal immunocompetent hosts, as is the case for many other highly infec- 
tious viruses. Studies have shown that only $\sim 0.1-0.6 \%$ of HSV isolates harbor ACV resistance. Even more surprising is that this number is approximately the same in isolates from ACVtreated and non-treated individuals, meaning this number represents the natural occurrence of ACV resistance in the viral population $(20,21)$. In very rare instances, ACV resistance has been observed in non-immunocompromised patients. Fortunately, these cases have not been associated with clinical failure and remain the exception $(22,23)$.

This is not always the case for immunocompromised patients. In such cases, ACV-resistant strains have been isolated from patients with persistent and disseminated diseases at a higher rate. Across different groups of immunocompromised patients, rates vary from 4 to $14 \%$, but do not seem to be increasing significantly or to pose a risk of increased resistance developing in the overall population $(21,24)$. Although no detailed data have been published regarding the point at which ACV-resistant strains appear after prolonged treatment, prolonged use of ACV and the severity of immunosuppression seem to play a part in the development of drug resistance in these groups (25).

Fortunately, foscarnet has been used with success following the development of ACV resistance, indicating a low cross-resistance of the two drugs, and few cases of foscarnet resistance have been reported in clinical practice $(24,25)$.

The explanation for the low rates of drug-resistant HSV isolates found in the normal population could lie in the latency established by the virus early during the infection process. In animal models, infected neurons can be detected as early as $24 \mathrm{~h}$ after infection. This makes it plausible that the early latency established by the virus is the source of all recurrent infections over the lifetime of the host. Therefore, although this latency makes the eradication of HSV nearly impossible with the antiviral agents currently available, it presents an important form of protection against the development of highly resistant strains, which could cause an HSV epidemic (24).

Mathematical models of HSV-2 drug resistance have predicted that the increased use of antiviral agents to treat HSV-2 will continue to cause minimal development of resistant strains, and will rather help to reduce the high prevalence of HSV in the population (26).

When looking more closely at the mutations which cause antiviral resistance to nucleoside drugs, it is not surprising that these mutations occur in the viral TK and DNA polymerase genes, where the following phenotypes can be distinguished: i) TK deficient (a complete lack of TK activity), ii) TK low producer (a reduced TK activity), iii) TK altered (a reduced specificity for nucleoside drugs) and iv) DNA polymerase altered (a reduced affinity for phosphorylated drugs). These phenotypes are caused by a variety of different mutations (reviewed in ref. 25), but most clinical isolates are TK deficient or TK altered. This is confirmed by studies which demonstrate that TK is not essential for virus replication in most tissues or cell cultures $(27,28)$. It also explains why mutations in the DNA polymerase that cause resistance to foscarnet or cidofovir are quite rare.

Although resistant strains of HSV do not currently pose a threat, in a number of decades it is likely that resistant strains will replace wild-type strains in treated individuals. Thus, we cannot rely on standard nucleoside analogue therapy to contain

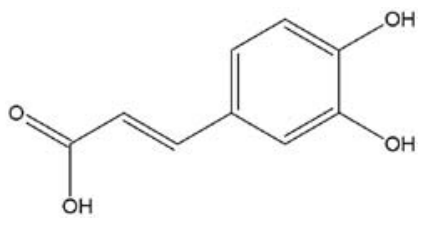

Figure 1. Structure of caffeic acid.
A.<smiles>C=CCc1ccc(O)c(OC)c1</smiles>

B.<smiles>COc1cc(/C=C/C(=O)CC(=O)/C=C/c2ccc(O)c(OC)c2)ccc1O</smiles>

C.

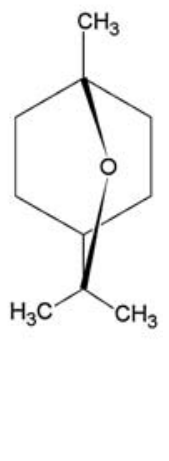

Figure 2. Molecular structure of several compounds found to be active against HSV in vivo by Bourne et al (30): (A) curcumin, (B) cineole and (C) eugenol.

HSV infections forever, and instead need to look in other directions for new treatment options. New targets for antiHSV drugs are already being investigated, and with some encouraging results (reviewed in ref. 29). Another promising domain for new HSV treatments, and one which needs further investigation, is that of natural products and their derivatives. In the past, these have repeatedly been shown to be an abundant resource for a variety of new and improved viral therapies. Thus, innumerable in vitro and some in vivo anti-HSV assays of thousands of substances and extracts have been evaluated over the past decades. This study aims to highlight the natural compounds that have shown promise as new candidates for clinical trials, as well as several that warrant further investigation as new anti-HSV agents.

\section{Natural products with anti-herpes simplex virus activity}

Caffeic acid, a phenolic compound, was shown to be one of the effective substances present in Plantago major (Fig. 1) (30,31). It has strong activity against $\mathrm{HSV}-1\left(\mathrm{EC}_{50}=15.3 \mu \mathrm{g} / \mathrm{ml}\right)$ and less activity against HSV-2 $\left(\mathrm{EC}_{50}=87.3 \mu \mathrm{g} / \mathrm{ml}\right)$. Structureactivity relationships have shown that reducing the number of hydroxyl groups also reduces activity against HSV-1 (32).

Another phenolic compound is curcumin (Fig. 2A), which is present in the curry spice turmeric and was recently found to inhibit immediate-early genes of HSV-1 by an unknown mechanism. It has been proven that recruitment of RNA polymerase II to the VP16 and IE promoters was significantly diminished, though independently of histone acetyltransferase activity (33). It has previously been shown that curcumin is moderately active against HSV-2 in vitro. This has led to an in vivo assay using a mouse model of intravaginal HSV-2 infections, where curcumin was found to provide significant $(\mathrm{p}<0.05)$ protection. In the same in vivo experiment a terpene, 


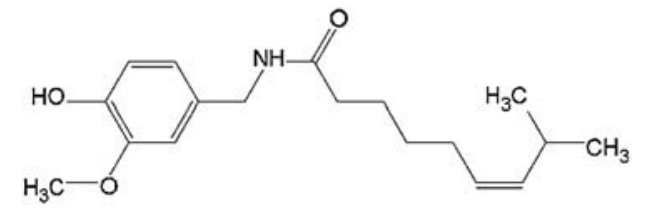

Figure 3. Molecular structure of civamide (cis-capsaicin).<smiles>O=C1C(O)=C(c2ccccc2)OC2C=C(O)C=C(O)C12</smiles><smiles>O=c1c(O)c(-c2ccc(O)cc2)oc2cc(O)cc(O)c12</smiles>

Figure 4. Structures of compounds from propolis exhibiting anti-HSV activity.

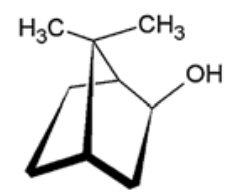

Figure 5. Structure of Isoborneol.

cineole (Fig. 2B), exhibited similar results to curcumin, while a phenolic, eugenol (Fig. 2C), demonstrated the most promising results in a mouse model.

This substance was then further investigated in a guinea pig model of HSV-2 infection, which more closely represents the infection in humans. Here, eugenol was again highly effective. Treatment resulted in significantly fewer animals $(\mathrm{p}<0.05)$ developing primary infection, and in a significant reduction $(p<0.005)$ in the virus titer of the animals that became infected. However, symptomatic infection in these animals had comparable severity to the controls (30). Benencia and Courreges confirmed the effectiveness of eugenol at inhibiting virus replication in vitro, as well as its ability to delay herpetic keratitis in mice after topical application (34). It was postulated that the phenolic nature of eugenol damages the envelope proteins of newly-synthesized virus particles (35), or that the mode of action of eugenol is related to its capsaicin-like properties, which allow it to interfere with virus-neuron interactions and lead to a decrease in the establishment of latency (30).

In animal models, capsaicin was shown to be rather effective against HSV. However, it was noxious when applied to the mucous membranes and caused an unpleasant burning sensation. Therefore, the less noxious cis-capsaicin civamide (Fig. 3) was also tested in an animal model. Civamide was shown to reduce the occurrence of primary infections when administered prior to virus challenge, or to reduce the infection when given after the virus challenge. Furthermore, civamide reduced the recurrence of latent infections when weekly treatment was continued as a suppressive maintenance therapy (36).

Another polyphenolic that clearly warrants further investigation is prodelphinidin B-2 3,3'-di-O-gallate (PB233'OG). Cheng et al (37) found that it inhibited HSV-2 with $\mathrm{IC}_{50}$ values of up to $0.4 \mu \mathrm{M}$. Notably, PB233'OG was found to be most effective during the early stages of HSV-2 infection, indicating an interference with virus penetration during the infection process. However, effects observed in the late stages of the infection cycle point towards the existence of multiple mechanisms by which PB233'OG may inhibit HSV-2 infection (37).

Propolis, or bee-glue, has long been recognized as a valuable natural product for antiviral treatments. Amoros et al (38) identified nine flavonoids from propolis which were tested for their effectiveness against HSV. Generally, flavonols were found to be more active than flavones, their activity increasing with the number of their hydroxyl substitutions. Combinations of flavones and flavonoids were also analyzed, showing that the synergistic effects of these substances account for the high antiviral activity of propolis. Of the substances tested, galangin and kaempferol (Fig. 4) had the highest anti-HSV activity, reducing the viral titer by $2 \log _{10}$ or more (38). This was confirmed by Lyu et al, who additionally demonstrated that the two substances had high anti-HSV in vitro activity, and that flavonols had higher activity than flavones (39).

Isoborneol (Fig. 5), a monoterpene found in several essential oils, was found to have interesting anti-HSV activity. Firstly, isoborneol was able to inactivate HSV within $30 \mathrm{~min}$ of exposure, and completely inhibited viral replication at low concentrations $(0.06 \%)$. In cell culture models, no cytotoxicity was found for concentrations of up to $0.08 \%$. In the presence of isoborneol, the glycosylation of certain viral polypeptides was inhibited, while the glycosylation of cellular proteins remained unchanged. When copies of these viral proteins were introduced into the cellular genome and expressed there, glycosylation was normal in the presence of isoborneol (40). This finding seems to indicate that isoborneol is a promising new candidate for HSV treatment.

Two more promising compounds were isolated from Rhus javanica and examined for their anti-HSV activity in vitro and in vivo by Kurokawa et al (41). Moronic and betulonic acid (Fig. 6) exhibited in vitro activity with $\mathrm{EC}_{50}$ values of 3.9 and $2.6 \mu \mathrm{g} / \mathrm{ml}$, respectively, though the therapeutic index of moronic acid was higher. Notably, the susceptibility of ACVresistant HSV-1, TK-deficient HSV-1 and wild-type HSV-2 to moronic acid was similar to that of wild-type HSV-1. This points towards a different mechanism of action than that had by ACV. When moronic acid was administered to mice cutaneously infected with HSV-1, skin lesions were significantly reduced, and the mean survival time was significantly increased compared to that of the control mice (41). Nawawi et al (42) evaluated the in vivo effectiveness of the alkaloid FK-3000 (Fig. 7) isolated from Stephania cepharantha. In mice subcutaneously infected with HSV-1, treatment with FK-3000 significantly reduced skin lesions and prolonged survival time. Unfortunately, the therapeutic index was shown to be 


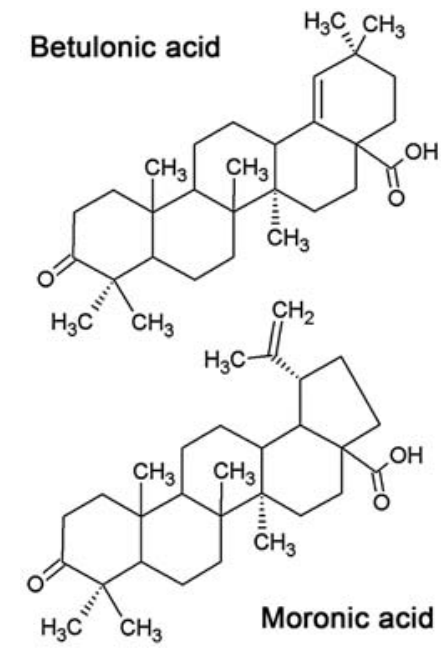

Figure 6. Anti-HSV compounds from Rhus javanica.

very narrow, demonstrating the need for further investigation in different models, such as herpes simplex keratitis (42).

Another antiviral substance, meliacine, was found to exhibit potent activity against HSV-1. Time-of-addition experiments have shown that meliacine acts in the late stages of the HSV-1 replication cycle. Specific infected-cell polypeptides, some of which play a part in DNA synthesis and in the assembly of nucleocapsids, were inhibited by the addition of meliacine (43). The same group also exhibited meliacine activity in vivo in a model of herpetic stromal keratitis in mice. Meliacine was administered topically 3 times a day for 4 days, beginning 1 day before inoculation. It was demonstrated that treatment with meliacine decreased clinical symptoms as well as histological damage to the cornea, and caused a 2-fold decrease in the viral titers detected in the eyes of infected and treated mice (44). This was confirmed by another study on murine herpetic stromal keratitis, where treatment $24 \mathrm{~h}$ post infection reduced viral replication by 1-1.5 orders of magnitude and prevented tissue damage in the corneas of treated mice (45).

One last group of anti-HSV compounds should be mentioned here. Several sulfated polysaccharides have been shown to possess anti-HSV activity, and many carrageenans (found mostly in red seaweed) have been shown to be active against HSV infections. Several in vitro studies have demonstrated $\mathrm{IC}_{50}$ values of 0.4-5.6 $\mu \mathrm{g} / \mathrm{ml}$ for different types of carrageenans (46-48), and several in vivo mouse models have also confirmed their effectiveness. In models of intravaginal HSV-2 infection, mice exhibited signs of significant protection $(30,48)$, and were also protected from intraperitoneal infection when carrageenan was administered immediately after infection. Protection was not improved when repeated hourly doses were administered at up to $48 \mathrm{~h}$ post infection, indicating that the substance plays a role early in the virus replication process. Indeed, treatment initiated $24 \mathrm{~h}$ post infection yielded no improvement compared to non-treated animals (49).

Another sulfated polysaccharide exhibiting antiviral effects is rhamnan sulfate, isolated from Monostroma latissimum. It has been shown to not only inhibit virus absorption and penetration, but also, in the later stages of HSV-1 infection, to inhibit virus replication (50).

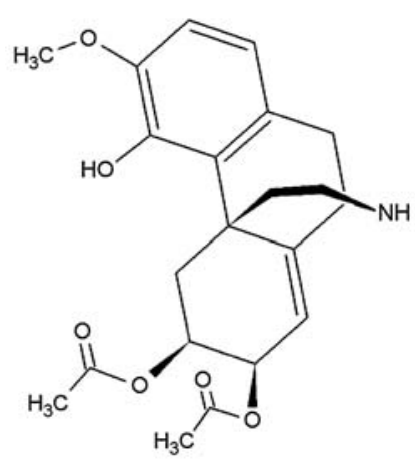

Figure 7. The anti-HSV alkaloid FK3000.

Galactofucans, from brown seaweed, were also found to possess anti-HSV properties $(51,52)$. One galactofucan was tested in vitro on several clinical HSV strains, including ACVresistant HSV-1 and -2 strains. Galactofucan was significantly more effective against HSV-2 than HSV-1, with $\mathrm{IC}_{50}$ values of 0.5 and $32 \mu \mathrm{g} / \mathrm{ml}$, respectively. The mode of action was the inhibition of viral penetrance into the host cell (52).

Calcium spirulan, a sulfated polysaccharide isolated from the blue-green algae Spirulina platensis, was found to be a potent inhibitor of HSV-1 replication (as well as of other enveloped viruses). On the basis of the results of time-ofaddition experiments, the main targets of this polysaccharide are believed to be the early stages of virus attachment and penetration. It has also been suggested that $\mathrm{Ca}$-SP interferes in the later stages of replication, after the virus has penetrated the host cells, and $\mathrm{Ca}^{2+}$ was shown to be essential for antiviral activity (53). More recently, it was demonstrated that replacing $\mathrm{Ca}^{2+}$ with $\mathrm{Na}^{+}$or $\mathrm{K}^{+}$maintained antiviral activity, while other divalent or trivalent metal ions reduced antiviral activity (54).

\section{Conclusions}

HSV infections have a very high prevalence worldwide, and are not expected to decrease significantly over the next few years. An increasing number of immunocompromised patients and increasingly prolonged administration of standard treatments might heighten the problems caused by drug-resistant HSVs. Even with the current high effectiveness of standard treatment and the low occurrence of drug resistance, the need for novel treatment options remains a pressing matter if possible future HSV epidemics are to be avoided.

The antiviral potential of natural products indicates that plants from ethnomedicine are a valuable resource for the development of new drugs. It is advisable that research in this area continues so that a large number of potential lead compounds may be identified. Even more importantly, research must proceed with synthetic derivatives of promising compounds in order to move beyond the initial identification of promising candidates in vitro.

Some compounds have already been tested in vivo. Of these, the most potent should undergo preclinical and clinical trials as well as toxicity testing in order to produce new treatment options, particularly for immunocompromised patients suffering from severe HSV infections. 
Finally, new methods such as gene expression profiling should increasingly be used to identify molecular targets for novel therapy options, as well as to further clarify the modes of action of the lead compounds which have already been found.

\section{References}

1. Nahmias AJ, Lee FK and Beckman-Nahmias S: Sero-epidemiological and -sociological patterns of herpes simplex virus infection in the world. Scand J Infect Dis 69 (Suppl): 19-36, 1990.

2. Smith JS and Robinson NJ: Age-specific prevalence of infection with herpes simplex virus types 2 and 1: a global review. J Infect Dis 186 (Suppl 1): 3-28, 2002.

3. Stevens JG: Latent herpes simplex virus and the nervous system. Curr Top Microbiol Immunol 70: 31-50, 1975.

4. Wheeler CE Jr: Pathogenesis of recurrent herpes simplex infections. J Invest Dermatol 65: 341-346, 1975.

5. Severson JL and Tyring SK: Relation between herpes simplex viruses and human immunodeficiency virus infections. Arch Dermatol 135: 1393-1397, 1999.

6. Thomas J and Rouse BT: Immunopathogenesis of herpetic ocular disease. Immunol Res 16: 375-386, 1997.

7. Xu F, Sternberg MR, Kottiri BJ, et al: Trends in herpes simplex virus type 1 and type 2 seroprevalence in the United States. JAMA 296: 964-973, 2006.

8. Freeman EE, Weiss HA, Glynn JR, Cross PL, Whitworth JA and Hayes RJ: Herpes simplex virus 2 infection increases HIV acquisition in men and women: systematic review and metaanalysis of longitudinal studies. AIDS 20: 73-83, 2006.

9. Wald A and Link K: Risk of human immunodeficiency virus infection in herpes simplex virus type 2-seropositive persons: a meta-analysis. J Infect Dis 185: 45-52, 2002.

10. Strick LB, Wald A and Celum C: Management of herpes simplex virus type 2 infection in HIV type 1-infected persons. Clin Infect Dis 43: 347-356, 2006.

11. Elion GB, Furman PA, Fyfe JA, De Miranda P, Beauchamp L and Schaeffer HJ: Selectivity of action of an antiherpetic agent, 9(2-hydroxyethoxymethyl) guanine. Proc Natl Acad Sci USA 74: 5716-5720, 1977.

12. Boyd MR, Bacon TH, Sutton D and Cole M: Antiherpesvirus activity of 9-(4-hydroxy-3-hydroxy-methylbut-1-yl)guanine (BRL 39123) in cell culture. Antimicrob Agents Chemother 31: 1238-1242, 1987 .

13. Earnshaw DL, Bacon TH, Darlison SJ, Edmonds K, Perkins RM and Vere Hodge RA: Mode of antiviral action of penciclovir in MRC- 5 cells infected with herpes simplex virus type 1 (HSV-1), HSV-2, and varicella-zoster virus. Antimicrob Agents Chemother 36: 2747-2757, 1992.

14. Elion GB: Acyclovir: discovery, mechanism of action, and selectivity. J Med Virol (Suppl 1): 2-6, 1993.

15. Ilsley DD, Lee SH, Miller WH and Kuchta RD: Acyclic guanosine analogs inhibit DNA polymerases alpha, delta, and epsilon with very different potencies and have unique mechanisms of action. Biochemistry 34: 2504-2510,1995.

16. Lowe DM, Alderton WK, Ellis MR, et al: Mode of action of (R)9-[4-hydroxy-2-(hydroxymethyl)butyl]guanine against herpesviruses. Antimicrob Agents Chemother 39: 1802-1808, 1995.

17. Chrisp P and Clissold SP: Foscarnet. A review of its antiviral activity, pharmacokinetic properties and therapeutic use in immunocompromised patients with cytomegalovirus retinitis. Drugs 41: 104-129, 1991.

18. De Clercq E: Therapeutic potential of Cidofovir (HPMPC, Vistide) for the treatment of DNA virus (i.e. herpes-, papova-, pox- and adenovirus) infections. Verh K Acad Geneeskd Belg 58: 19-49, 1996.

19. Ho HT, Woods KL, Bronson JJ, De Boeck H, Martin JC and Hitchcock MJ: Intracellular metabolism of the antiherpes agent (S)-1-[3-hydroxy-2-(phosphonylmethoxy)propyl]cytosine. Mol Pharmacol 41: 197-202, 1992

20. Boon RJ, Bacon TH, Robey HL, et al: Antiviral susceptibilities of herpes simplex virus from immunocompetent subjects with recurrent herpes labialis: a UK-based survey. J Antimicrob Chemother 46: 1051, 2000.

21. Christophers J, Clayton J, Craske J, et al: Survey of resistance of herpes simplex virus to acyclovir in northwest England. Antimicrob Agents Chemother 42: 868-872, 1998.

22. Kost RG, Hill EL, Tigges M and Straus SE: Brief report: recurrent acyclovir-resistant genital herpes in an immunocompetent patient. N Engl J Med 329: 1777-1782, 1993.
23. Swetter SM, Hill EL, Kern ER, et al: Chronic vulvar ulceration in an immunocompetent woman due to acyclovir-resistant, thymidine kinase-deficient herpes simplex virus. J Infect Dis 177: 543-550, 1998 .

24. Field HJ: Herpes simplex virus antiviral drug resistance - current trends and future prospects. J Clin Virol 21: 261-269, 2001.

25. Gilbert C, Bestman-Smith J and Boivin G: Resistance of herpesviruses to antiviral drugs: clinical impacts and molecular mechanisms. Drug Resist Updat 5: 88-114, 2002.

26. Blower S: Modelling the genital herpes epidemic. Herpes 11 (Suppl 3): 138A-146A, 2004.

27. Gaudreau A, Hill E, Balfour HH Jr, Erice A and Boivin G: Phenotypic and genotypic characterization of acyclovir-resistant herpes simplex viruses from immunocompromised patients. J Infect Dis 178: 297-303, 1998.

28. Morfin F, Souillet G, Bilger K, Ooka T, Aymard M and Thouvenot D: Genetic characterization of thymidine kinase from acyclovir-resistant and -susceptible herpes simplex virus type 1 isolated from bone marrow transplant recipients. J Infect Dis 182: 290-293, 2000.

29. Greco A, Diaz JJ, Thouvenot D and Morfin F: Novel targets for the development of anti-herpes compounds. Infect Disord Drug Targets 7: 11-18, 2007.

30. Bourne KZ, Bourne N, Reising SF and Stanberry LR: Plant products as topical microbicide candidates: assessment of in vitro and in vivo activity against herpes simplex virus type 2 . Antiviral Res 42: 219-226, 1999.

31. Dimitrova Z, Dimov B, Manolova N, Pancheva S, Ilieva D and Shishkov S: Antiherpes effect of Melissa officinalis L. extracts. Acta Microbiol Bulg 29: 65-72, 1993.

32. Chiang LC, Chiang W, Chang MY, Ng LT and Lin CC: Antiviral activity of Plantago major extracts and related compounds in vitro. Antiviral Res 55: 53-62, 2002.

33. Kutluay SB, Doroghazi J, Roemer ME and Triezenberg SJ: Curcumin inhibits herpes simplex virus immediate-early gene expression by a mechanism independent of p300/CBP histone acetyltransferase activity. Virology 373: 239-247, 2008.

34. Benencia F and Courreges MC: In vitro and in vivo activity of eugenol on human herpesvirus. Phytother Res 14: 495-500, 2000.

35. Serkedjieva J and Manolova N: Plant polyphenolic complex inhibits the reproduction of influenza and herpes simplex viruses. Basic Life Sci 59: 705-715, 1992.

36. Bourne N, Bernstein DI and Stanberry LR: Civamide (ciscapsaicin) for treatment of primary or recurrent experimental genital herpes. Antimicrob Agents Chemother 43: 2685-2688, 1999.

37. Cheng HY, Lin TC, Ishimaru K, Yang CM, Wang KC and Lin CC: In vitro antiviral activity of prodelphinidin B-2 3,3'-di-O-gallate from Myrica rubra. Planta Med 69: 953-956, 2003.

38. Amoros M, Simoes CM, Girre L, Sauvager F and Cormier M: Synergistic effect of flavones and flavonols against herpes simplex virus type 1 in cell culture. Comparison with the antiviral activity of propolis. J Nat Prod 55: 1732-1740, 1992.

39. Lyu SY, Rhim JY and Park WB: Antiherpetic activities of flavonoids against herpes simplex virus type 1 (HSV-1) and type 2 (HSV-2) in vitro. Arch Pharm Res 28: 1293-1301, 2005.

40. Armaka M, Papanikolaou E, Sivropoulou A and Arsenakis M: Antiviral properties of isoborneol, a potent inhibitor of herpes simplex virus type 1. Antiviral Res 43: 79-92, 1999.

41. Kurokawa M, Basnet P, Ohsugi M, et al: Anti-herpes simplex virus activity of moronic acid purified from Rhus javanica in vitro and in vivo. J Pharmacol Exp Ther 289: 72-78, 1999.

42. Nawawi A, Nakamura N, Meselhy MR, et al: In vivo antiviral activity of Stephania cepharantha against herpes simplex virus type-1. Phytother Res 15: 497-500, 2001.

43. Alche LE, Barquero AA, Sanjuan NA and Coto CE: An antiviral principle present in a purified fraction from Melia azedarach $L$. leaf aqueous extract restrains herpes simplex virus type 1 propagation. Phytother Res 16: 348-352, 2002.

44. Alche LE, Berra A, Veloso MJ and Coto CE: Treatment with meliacine, a plant derived antiviral, prevents the development of herpetic stromal keratitis in mice. J Med Virol 61: 474-480, 2000.

45. Pifarre MP, Berra A, Coto CE and Alche LE: Therapeutic action of meliacine, a plant-derived antiviral, on HSV-induced ocular disease in mice. Exp Eye Res 75: 327-334, 2002.

46. Carlucci MJ, Ciancia M, Matulewicz MC, Cerezo AS and Damonte EB: Antiherpetic activity and mode of action of natural carrageenans of diverse structural types. Antiviral Res 43: 93-102, 1999.

47. Carlucci MJ, Scolaro LA and Damonte EB: Inhibitory action of natural carrageenans on Herpes simplex virus infection of mouse astrocytes. Chemotherapy 45: 429-436, 1999. 
48. Talarico LB, Zibetti RG, Faria PC, et al: Anti-herpes simplex virus activity of sulfated galactans from the red seaweeds Gymnogongrus griffithsiae and Cryptonemia crenulata. Int $\mathbf{J}$ Biol Macromol 34: 63-71, 2004.

49. Pujol CA, Scolaro LA, Ciancia M, Matulewicz MC, Cerezo AS and Damonte EB: Antiviral activity of a carrageenan from Gigartina skottsbergii against intraperitoneal murine herpes simplex virus infection. Planta Med 72: 121-125, 2006.

50. Lee JB, Hayashi K, Hayashi T, Sankawa U and Maeda M: Antiviral activities against HSV-1, HCMV, and HIV-1 of rhamnan sulfate from Monostroma latissimum. Planta Med 65: 439-441, 1999.

51. Ponce NM, Pujol CA, Damonte EB, Flores ML and Stortz CA: Fucoidans from the brown seaweed Adenocystis utricularis: extraction methods, antiviral activity and structural studies. Carbohydr Res 338: 153-165, 2003.
52. Thompson KD and Dragar C: Antiviral activity of Undaria pinnatifida against herpes simplex virus. Phytother Res 18 551-555, 2004.

53. Hayashi K, Hayashi T and Kojima I: A natural sulfated polysaccharide, calcium spirulan, isolated from Spirulina platensis: in vitro and ex vivo evaluation of anti-herpes simplex virus and anti-human immunodeficiency virus activities. AIDS Res Hum Retroviruses 12: 1463-1471, 1996.

54. Lee JB, Srisomporn P, Hayashi K, Tanaka T, Sankawa U and Hayashi T: Effects of structural modification of calcium spirulan, a sulfated polysaccharide from Spirulina platensis, on antiviral activity. Chem Pharm Bull (Tokyo) 49: 108-110, 2001. 